\title{
KEARIFAN LOKAL MASYARAKAT DALAM MELESTARIKAN LEBAH MADU ALAM DENGAN TEKNIK TIKUNG DI KAWASAN SIAWAN BELIDA KAPUAS HULU
}

\author{
( The Local Wisdom of The Community In Preserving Natural Honey Bees with Tikung \\ Techniques In The Ares of Siawan Belida, Nanga Tuan village, Bunut Hilir subdistrict, Kapuas \\ Hulu Regency)
}

\author{
Jamiat, Iskandar, M. Idham \\ Fakultas Kehutanan Universitas Tanjungpura, Jalan Imam Bonjol Pontianak, 78124 \\ Email: jamiatfahutan@gmail.com
}

\begin{abstract}
Local wisdom is one of the characteristics national culture that deserves to be explored and developed in the future. Honey production is carried out by maintaining traditional nest making that utilizes natural materials are local wisdom that is still applied. The purpose of this study is to (1) reveal the local wisdom in natural forest honey management, (2) the amount of natural forest honey produced by the community from periau using tikung techniques in the area of Siawan Belida, Nanga Tuan Village, Bunut Hilir Subdistrict, Kapuas Hulu Regency. The method used a survey with interview techniques, the selection of respondents are choosing all Nanga Tuan periau. The results of the study revealing local wisdom in preserving natural honey bees with tikung techniques in the Siawan Belida area, namely; tikung, making tikung, selecting trees for installation of tikung, agreement on division of territory in lakes (suak), sanctions for tree destroyers, sanctions for tikung hives burglars, pre-harvesting ceremonies, conditions of harvesting natural forest honey, harvesting honey bees process, honey treatment after harvesting at home. Tree preservation efforts of tikung honey bee techniques based on local wisdom, including; stipulation of forest lake areas in the management of tikung honey, types of feed for Apis dorsata bees. The amount of natural forest honey is 5- 8 tons / year with planting done twice / year.
\end{abstract}

Keywords : local wisdom, natural honey bees, Siawan Belida, tikung techniques

\section{PENDAHULUAN}

Madu hutan merupakan hasil hutan bukan kayu yang dikelolola masyarakat sekitar hutan yang mewujudkan pelestarian hutan, membantu komunitas masyarakat lokal, alternatif pendapatan bagi warga setempat, menjaga keberlangsunan penyerbukan tumbuhan. Melestarikan madu hutan, masyarakat sekitar hutan memiliki berbagai nilai yang diciptakan, dikembangkan dan dipertahankan oleh masyarakat yang menjadi pedoman hidup mereka, pedoman ini bisa tergolong dalam jenis kaidah sosial, baik secara tertulis ataupun tidak tertulis, akan tetapi masyarakat mencoba mentaatinya yaitu kearifan lokal masyarakat sekitar hutan (Apriyanto 2008). Kearifan lokal juga tidak lepas dari berbagai tantangan seperti bertambanya jumlah penduduk, teknologi modern dan budaya, modal besar serta kemiskinan dan kesenjangan (Suhartini 2009).

Kearifan lokal dibangun dari nilainilai sosial yang dijunjung dalam 
struktur sosial masyarakat sendiri dan memiliki fungsi sebagai pedoman, pengontrol dan rambu-rambu untuk berperilaku dalam berbagai dimensi kehidupan baik saat berhubungan dengan sesama maupun alam (Santoso 2006). Kearifan lokal dapat dijadikan komponen penting untuk melaksanakan upaya penyelamatan sumberdaya genetik tanaman hutan (Sartini 2004). Kearifan lokal masyarakat Desa Nanga Tuan dalam pelestarian madu terwujud pada nilai-nilai konservasi.

Pelestarian lebah madu alam dilakukan dengan berbagai cara dengan tujuan menghasilkan jumlah lebah madu alam yang lebih banyak. Pembuatan sarang secara tradisional salah satu nya dengan cara tikung (sarang buatan) yakni memberi tempat untuk bersarang bagi lebah madu alam atau dapat pula dikatakan membuat mikro habitat untuk koloni lebah madu alam. Penggunaan tikung oleh masyarakat Dusun Siawan Desa Nanga Tuan dimanfaatkan pada Kawasan Danau Siawan Belida. Pembuatan kayu tikung berdasarkan dari jenis kayu medang, rengas dan kawi. Tikung adalah tempat hinggap dan sarang lebah madu alam (Apis dorsata) yang dibuat dari kayu berbentuk papan dan ditemapatkan sedemikian rupa pada pohon-pohon penghasil pakan lebah madu alam pada saat air pasang surut yang mengantung di tikung tersebut terendam air (FORCLIME-FC 2017).

Tujuan penelitian ini adalah mengungkapkan kearifan lokal pengelolaan lebah madu alam dengan teknik tikung di Kawasan Siawan Belida dan mengungkapkan besarnya hasil lebah madu alam yang diperoleh masyarakat dan penggunaan teknik tikung di Kawasan Siawan Belida Desa Nanga Tuan Kecamatan Bunut Hilir Kabupaten Kapuas Hulu.

\section{METODE PENELITIAN}

Penelitian ini dilaksanakan di Kawasan Siawan Belida Desa Nanga Tuan Kecamatan Bunut Hilir Kabupaten Kapuas Hulu. Subjek penelitian adalah anggota petani madu (periau) masyarakat dalam melestarikan lebah madu alam teknik tikung. Objek penelitian adalah kegiatan masyarakat yang melestarikan lebah madu alam dengan teknik tikung. Alat yang digunakan adalah daftar wawancara, kamera, peta lokasi, GPS (Global Position System), alat tulis dan smartphone (perekam suara). Metode yang digunakan adalah metode survey dengan teknik wawancara, pemilihan responden dilakukan dengan sensus atau semua periau Nanga Tuan. Analisis data menggunakan metode deskriptif kualitatif dengan menggambarkan atau melukiskan keadaan subjek dan objek penelitian.

\section{HASIL DAN PEMBAHASAN Kearifan Lokal Pengolahan Lebah} Madu Alam

\section{Tikung}

Pembuatan sarang lebah madu alam tikung didapatkan penduduk sekitar siawan belida dari pengalaman yang diwariskan turun temurun sejak nenek moyang mereka. Dijelaskan pula oleh masyarakat awalnya mendapatkan 
pengetahuan pembuatan sarang buatan ini diperoleh dari melihat kayu yang tersangkut pada percabangan pohon saat terjadi pasang disekitar danau pada waktu air surut, kayu yang tertinggal di pohon di sarangi lebah madu alam atas dasar pegalaman yang dilihat tersebut maka pengalaman masyarakat diwariskan generasi ke generasi selanjutnya hingga sekarang.

Tahap awal pembuatan tikung melakukan pemilihan kayu pohon hutan yang sudah tumbang/roboh dengan demikian kearifan lokal masyarakat atau periau memanfaatkan hasil hutan yang ada tanpa merusak ekosistem lingkungan disekitar. Kuntadi (2007) menjelaskan, jenis kayu untuk membuat tempat sarang bagi lebah madu alam sebaiknya kayu yang kuat yang terdapat di daerah asal, hal ini dilakukan oleh periau APBS Nanga Tuan agar sarang madu pada jenis kayu tertentu dapat meningkatkan jumlah produksi yang banyak.

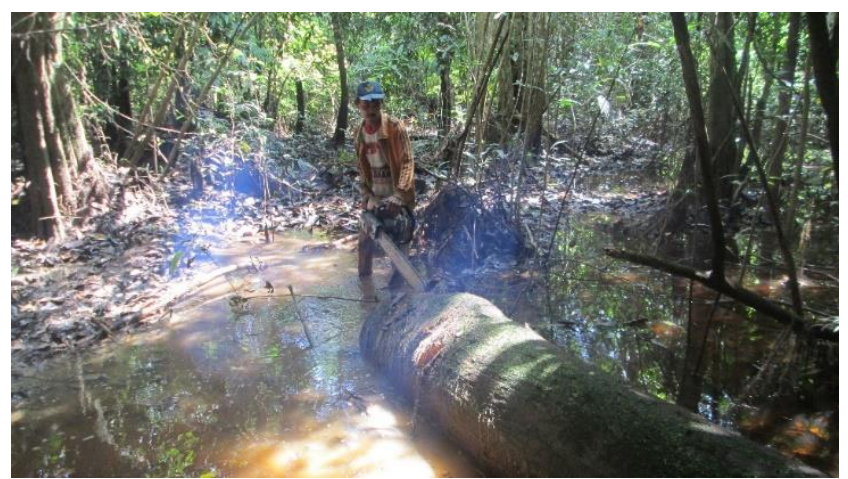

Gambar 1. Petani melalukan pembelahan kayu bulat jenis Rengas (Gluta renghas) (The farmer are splitting wood)

\section{Pembuatan tanda tikung}

Pemberian kode pada tikung dilakukan bertujuan supaya tikung yang telah dipasang di pohon nantinya tidak tertukar dengan tikung anggota lainnya. Tidak hanya pemberian tanda terhadap tikung, pemberian tanda juga dilakukan di pohon tempat pemasangan tikung. Setelah tahap pembuatan tikung telah dilakukan tahap akhir ialah petani lebah madu alam di Desa Nanga Tuan melakukan pemberian tanda kepemilikan disetiap anggota petani (periau) lebah madu alam diantaranya dengan cara pemodelan pembuatan takik dan pemberian cat pada setiap tikung yang dipasang 


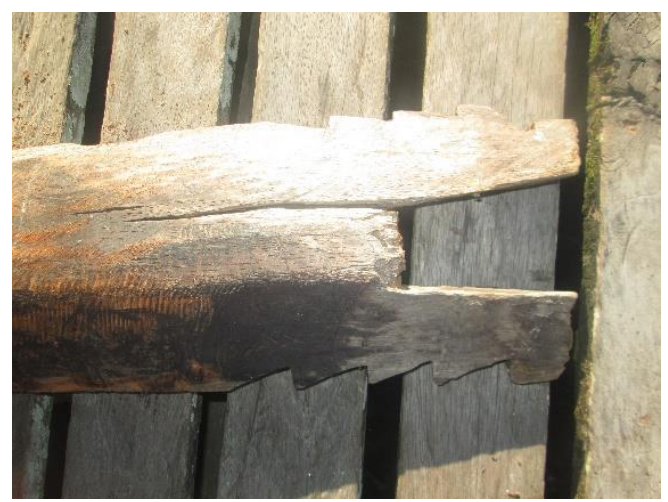

Gambar 2. Pemodelan takik (Styling of takik)

\section{Pemilihan Pohon untuk Pemasangan Tikung}

Pemasangan tikung harus melihat kondisi pohon, apabila pohon tersebut rindang dan percabangan yang banyak dapat dipasang $2-3$ tikung dengan jarak pasang antar tikung $2-3$ meter, sedangkan jika pohon tersebut tidak rindang dan ukuran pohon yang kecil hanya bisa dipasang satu tikung, kemudian tikung yang telah dipasang dioleskan lilin madu dan pemasangan tikung mengikuti arah mata angin. Pemasangan tikung harus ditengahtengah rindangnya pohon dan tidak boleh dipasang pada tajuk pohon yang terbuka dikarenakan banyak faktor yang mengganggu atau merusak tikung yang sudah dipasang seperti angin dan hewan.

Ketinggian pemasangan tikung dari tanah ke percabangan kurang lebih $10-$ 15 meter. Penentuan waktu dalam pemasangan tikung tidak ditentukan, biasanya petani madu hutan alam melakukan pemasangan saat siang hari serta dilakukan pembersihan terhadap pohon dan akses menuju ke pohon tersebut. Tikung yang telah di pasang oleh petani terkadang dalam waktu tertentu tidak dihinggapi oleh lebah madu alam (Apis dorsata) dikarenakan pengaruh terhadap cahaya matahari, untuk itu petani lebah madu alam melakukan pemutaran pada tikung di posisi yang sama atau pemindahan tikung ke posisi yang lebih tinggi dan pemindahan tikung ke posisi percabangan yang lain.

\section{Kesepakatan Pembagian Wilayah di Danau (suak).}

Setiap anggota petani lebah madu alam di Desa Nanga Tuan memiliki wilayah tertentu dilingkungan danau (suak) yang diwarisi dari anggota keluarga petani (periau) sebelumnya dan telah disepakati bersama. Dalam satu wilayah danau tertentu (suak) yang telah dimiliki satu anggota petani tidak boleh lagi bagi anggota petani lain untuk memasang tikung di areal tersebut. Bila petani (periau) lain melakukan pemasangan tikung di areal tersebut haruslah mendapatkan izin dari petani yang menguasai kawasan suak tersebut.

\section{Sanksi Perusak Pohon}

Sanksi adat yang tidak tertulis yang disepakati dan ditaati secara bersama yang berbunyi "barang siapa yang 
sengaja menebang atau merusak pohon pakan lebah serta membakar akan dikenakan denda Rp. 500.000,-/satu pohon".

\section{Sanksi Pencuri Sarang Lebah Madu Tikung}

Pemberian sanksi bagi seseorang yang melakukan pencurian sarang tikung ini didasarkan kepada kesepakatan adat masyarakat bunut hilir yang dituangkan secara tertulis dalam hasil kesepakatan adat. Menurut Hukum Adat Pasal 75 yang berbunyi "Apabila tikung berkongsi dengan orang lain, apabila orang membuat tikung, yang salah seorang mengambil dahulu mengambil madu tidak bermufakat dengan ahli waris, maka dituduh mencuri dan dihukum lepas berkongsi tikung tersebut. Jika seseorang melakukan pencurian sarang tikung milik orang lain, maka dikenakan sanksi adat berupa uang sebesar Rp. 750.000,-/sarang. Selanjutnya dijelaskan Pasal 77 Hukum Adat Bunut Hilir menyebutkan bahwa "Tikung yang sudah tidak dipelihara ahli waris selama 3 tahun, maka orang lain boleh memelihara, mengganti tikung tersebut dan memiki.

\section{Upacara Sebelum Pemanenan}

Periau Asosiasi Petani Bunut Singkar (APBS) Nanga Tuan memiliki budaya/nilai leluhur sebelum melakukan pemanenan. Hal yang dilakukan adalah berkumpul di rumah ketua anggota periau (petani madu) untuk melakukan do'a bersama sambil menghidangkan makanan dan minuman. Ritual religius ini dilakukan untuk mendoakan agar panen yang dilakukan berhasil dengan jumlah yang banyak dan juga keselamatan. Ritual berkumpul ini dilakukan pada malam hari.

8. Syarat Pemanena Lebah Madu Alam

\section{a. Pemanenan Madu Hutan Secara Lestari}

Teknik pemanenan lestari yang dimaksud ialah pemanenan dilakukan pada siang hari dan sarang yang berisi madu tidak diambil semua, ditinggalkan sekitar 2-3 cm agar lebah kembali lagi bersarang di tempat yang sama. Alasan dilakukannya panen siang hari adalah agar madu yang diperoleh lebih bersih dan tidak ada daun atau ranting yang masuk tergabung dengan madu yang diambil dan pemanenan di siang hari periau memiliki pandangan yang lebih leluasa sehingga mengurangi resiko periau jatuh dari pohon, terhindar dari binatang buas yang terkadang dialami saat panen dimalam hari. Sarang yang berisi anakan atau larva juga ditinggalkan supaya lebah selanjutnya tetap tumbuh.

\section{b. Panen Secara Tradisional}

Cara panen tradisional yang dahulu diterapkan oleh petani madu di Desa Nanga Tuan ialah pemanenan di lakukan pada malam hari dan pengambilan sarang berisi madu maupun anakan (larva) dipanen semua, anakan yang dipanen biasanya dijadikan untuk pakan ikan dan juga untuk dikonsumsi oleh petani madu (periau) lainnya. Menurut Cerita nenek moyang periau, melakukan panen pada malam 
hari dikarenakan ketika panen menggunakan bara api/pengasapan dalam proses pemanenan, lebah mengira bahwa bara api yang jatuh ke air merupakan intan dan lebah mengejar kebawah air ketika diwaktu pagi lebah naik lagi menghinggap ke sarang yang sama. Berdasarkan pelatihan-pelatihan yang didapat petani madu mengenai proses pemanenan, pemanenan yang dilakukan pada malam hari dapat menyebabkan kemungkinan ratu lebah jenis Apis dorsata ini mati dalam proses pemanenan. Apabila kemungkinan itu terjadi, lebah madu alam akan lama untuk menghinggapi sarang tikung butuh waktu yaitu $4-5$ tahun.

\section{c. Waktu Kesepakatan Bersama}

Petani Desa Nanga Tuan memiliki kesepakatan bahwa pemanenan harus dilakukan dengan bersama-sama dengan petani lain, ketua kelompok menentukan kapan waktu pemanenan akan dilaksanakan. Waktu yang ditetapkan oleh Ketua kelompok harus ditaati oleh anggota petani lain, sebelum ditetapkannya waktu pemanenan, terlebih dahulu beberapa petani meninjau ke kawasan Siawan Belida untuk melihat sarang yang berisi madu sudah siap dipanen dengan ciri-ciri lebah tersebut sudah tersusun dengan rapi di sarang.

\section{Proses Panen Lebah Madu}

\section{a. Persiapan}

- Memeriksa sarang lebah sebelum memulai pemanenan.

- Mempersiapkan pengamanan atau perlindungan, seperti : waren (jaring-jaring), topi, sarung tangan dari bahan karet.

- Mempersiapkan tronong (ember), tempat madu, wadah madu waktu diambil dari sarang, tebaok (bahan untuk pengasapan), pisau stainless.

- Membawa wadah tertutup seperti : ember atau baskom yang tertutup, terpal untuk menutup wadah hasil panen yang akan dibawa pulang.

\section{b. Pembuatan Tebaok untuk}

\section{Pengasapan}

Tebaok terbuat dari akar pohon jabai (Ficus sp.) pengambilan dengan mengunakan pisau dengan panjang akar pohon jabai (Ficus sp.) yang akan dipotong $100 \mathrm{~cm}$. Membuat tebaok terlebih dahulu akar tersebut dipukulpukul sampai pecah selanjutnya akar pohon jabai dikeringkan dengan pengasapan dan diikat dengan rotan.

\section{c. Pengasapan}

Tebaok ini dibakar dahulu sebelum petani madu (periau) memanjat pohon dapat dilihat pada Gambar 2. Tebaok dibawa bersama petani ke atas, asap yang dihasilkan tidaklah berbahaya bagi lebah hanyalah mengusir lebah sesaat dari sarang yang berisi madu pada saat panen.

\section{d. Pemanenan}

Proses pemanenan periau Nanga Tuan bekerja sama dengan petani lainnya berjumlah 2 hingga 3 orang untuk mempermudah pekerjaan. Petani yang memanjat pohon untuk memanen madu berjumlah 2 orang dengan tugas masing-masing ialah sebagai pemotong madu dan juga sebagai pemegang tronong dan tebaok, sedangkan petani 
yang dibawah mengambil hasil madu yang telah di panen oleh 2 petani yang berada di atas, apa yang dilakukan oleh kelompok dalam pemanenan madu (muar muanyi) ini merupakan sikap gotong royong dalam melakukan pekerjaan dan telah melekat pada diri masyarakat desa Nanga Tuan dan merupakan kebiasan turun temurun dari nenek moyang.

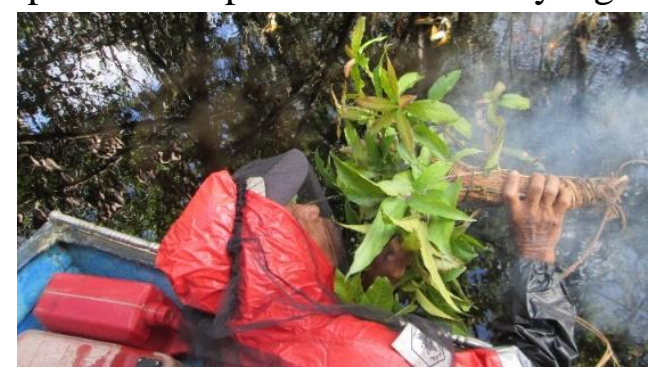

Gambar 3. Petani memulai proses pengasapan sebelum memulai pemanenan (Starting fumigation bofere harvesting)

\section{Pengolahan Madu}

Madu yang telah di panen oleh periau Nanga Tuan langsung dipindahkan dari tronong (ken khusus) ke ember penampung, setelah semua hasil panen madu telah selesai, hasil madu yang telah didapatkan akan diolah dirumah mengikuti prosedur yang telah ditetapkan oleh standar koperasi. Pengolahan madu di lakukan dengan cara ditiris di atas kain kasa yang berwadah ember. Proses ditiris bertujuan untuk memisahkan sarang dengan madunya dengan catatan harus menggunakan sarung tangan dan tidak dengan memeras madu agar madu yang dihasilkan mendapatkan kualitas madu yang lebih baik dan mengurangi kadar air. Proses ini diterapkan periau Nanga Tuan sesudah mengikuti bimbingan dari Lembaga Swadaya Masyarakat (LSM), sebelumnya kearifan lokal petani lebah madu alam (periau) Nanga Tuan masih menerapkan proses pengolahan dengan cara memeras madu. Proses selanjutnya ialah memasukan madu yang telah ditiriskan ke dalam jirigen dan siap di pasarkan.

Pelestarian Pohon Pakan Lebah Madu Alam di Kawasan Siawan Belida Desa Nanga Tuan Kecamatan Bunut Hilir Kabupaten Kapuas Hulu

1. Kawasan Siawan Belida dalam Pengelolaan Madu Tikung

Penentuan kawasan Danau hutan yang cocok untuk pohon penghasil lebah madu alam dan tingkat ketersediaan pohon pakan di kawasan Danau yang ditetapkan. Pemilihan Kawasan Danau yang cocok didasarkan oleh teknik pemanenan secara lestari ialah Kawasan Danau yang terhindar dari kegiatan-kegiatan yang dapat merusak ekosistem yang ada di hutan seperti penebangan liar, tambang serta kerusakan lainnya. Hutan yang dapat dijadikan sebagai pemasangan sarang lebah buatan juga diutamakan memiliki tingkat ketersediaan pohon yang banyak dan juga berbagai macam jenis pohon sehingga madu yang akan dihasilkan berjumlah banyak. Sejalan dengan pendapat yang diungkapkan oleh 
Julmansyah (2010) bahwa secara teoritis, kesehatan dan kelestarian hutan merupakan prasyarat bagi usaha madu hutan yang berkesinambungan, sehingga dalam pemilihan kawasan hutan yang tepat untuk tempat bersarangnya lebah madu mengutamakan kawasan hutan yang masih bagus dan terhindar dari kerusakan.

2. Jenis Pakan untuk lebah Apis dorsata di Kawasan Siawan Belida

Jenis-jenis bunga sebagai pakan lebah madu alam sangat berpengaruh dengan hasil produksi dan kualitas madu yang dihasilkan, pada bulan yang sudah ditentukan sebagai musim bunga untuk bermekaran maka lebah lebih banyak memproduksi madu, sedangkan pada saat beberapa jenis bunga yang tidak mekar maka terdapat sebagian lebah yang tidak memproduksi madu. Desa Nanga Tuan dikelilingi oleh danau yang menghasilkan jenis pohon untuk pakan lebah madu alam yang berlimpah. Dibawah ini dapat dilihat jenis bunga pohon yang dijadikan sebagai pohon penghasil madu alam dibawah ini:

Tabel 1. Jenis bunga pohon penghasil madu alam (Trees species that produces natural honey)

\begin{tabular}{|c|c|c|}
\hline No & Nama Jenis & Nama Ilmiah \\
\hline 1 & Ubah & Syzigium leptostemon \\
\hline 2 & Rengas & Gluta renghas \\
\hline 3 & Tempurau & Dipterocarpaceae spp \\
\hline 4 & Samak & Sygium sp. \\
\hline 5 & Kawi & Shorea balangeran \\
\hline 6 & Kayu tahun & Garcinia sp \\
\hline 7 & Putat & Barringtonia actutangula \\
\hline 8 & Medang & Litsea resinosa \\
\hline 9 & Kebesi & Memecylon edule \\
\hline 10 & Embasung & Syzygium claroflora \\
\hline 11 & Kerminit & Timonius flavescens \\
\hline 12 & Mutun & Teysmanniodendron sarawakanum \\
\hline 13 & Tapang & Melicope lunu-ankenda \\
\hline & Kebaca & Gluta pubescens \\
\hline & $\begin{array}{l}\text { Berdasarkan hasil penelitian, jenis } \\
\text { in yang paling mendominasi } \\
\text { tara jenis pakan lainnya di Tabel } 1 \\
\text { ah jenis pohon putat (Barringtonia } \\
\text { tangula) dan kayu tahun (Garcinia } \\
\text { Menurut petani lebah madu alam } \\
\text { iau) desa Nanga Tuan madu alam } \\
\text { dihasilkan dari pakan lebah jenis } \\
\text { but menghasilkan madu alam yang } \\
\text { kental. Riak Bumi (2012) madu } \\
\text { rasanya paling enak dan manis } \\
\text { berbagai jenis bunga pakan lebah } \\
n \text { ini adalah dari bunga akar libang, }\end{array}$ & $\begin{array}{l}\text { emasung, taun, kayu samak dan } \\
\text { marbemban. Periau Nanga Tuan } \\
\text { memberikan pakan tambahan dengan } \\
\text { menanam pohon di pinggir Danau. } \\
\text { Pohon yang ditanam sebagai pakan } \\
\text { tambahan adalah jenis pohon putat } \\
\text { (Barringtonia actutangula). } \\
\text { Disepanjang sungai Batang Bunut } \\
\text { hanya masyarakat di Desa Nanga Tuan } \\
\text { yang tidak melakukan aktifitas } \\
\text { penambangan emas tanpan ijin yang } \\
\text { dapat merusak ekosistem yang ada } \\
\text { dilingkungan sungai Batang Bunut }\end{array}$ \\
\hline
\end{tabular}


termasuk juga Kawasan Siawan Belida. Sehingga, ancaman utama yang dapat merusak ekosistem Kawasan Siawan Belida adalah kegiatan penambangan emas tanpa ijin. Masyarakat Desa Nanga Tuan menyadari bahwa kegiatan tersebut sangat merusak lingkungan yang akan mengakibatkan hilangnya sumber mata pencaharian mereka. Petani lebah madu alam (Periau) harus mengikuti peraturan dalam mekanisme pengelolaan madu alam yang telah di tetapkan. Jenis pohon pakan lebah madu alam dan juga pohon tempat lebah madu alam bersarang tidak boleh dilakukan pembakaran dan ditebang.

\section{Besar Hasil Lebah Madu Alam dari Penggunaan Teknik Tikung}

Periau Nanga Tuan melakukan pemanenan dalam jangka waktu setahun sebanyak 2 kali, diperkirakan jumlanya berkisar antara 100-150 kg untuk setiap periau dalam waktu sekali penan, total yang didaptkan 5-8 ton per tahun. Namun, diawal tahun 2019 untuk panen pertama jumlah madu alam yang dihasilkan mencapai 5-10 ton. Adapun faktor yang menyebabkan hasil panen menurun ialah asap yang dihasilkan dari kegiatan penambangan emas dan faktor alam yaitu angin yang membuat sarang tikung jatuh dan tidak dapat dipanen. Penambangan emas menimbulkan suara yang membuat lebah Apis dorsata lari sehingga tikung yang dipasang tidak dihinggap dan menyebabkan panen menurun. Panen pertama dilakukan dari bulan Januari sampai Feburari, sedangkan panen kedua dilakukan dari bulan November hingga Desember.
Widhiono (1986) menjelaskan bahwa faktor-faktor yang mempengaruhi produksi madu yaitu ketersedian pakan, cuaca, kelembaban, temperatur udara dan proporsi koloni lebah.

\section{KESIMPULAN}

1. Kearifan lokal masyarakat dalam melestarikan lebah madu alam dengan teknik tikung

di Kawasan Siawan Belida yaitu diantaranya; tikung, pembuatan tikung, pemilihan pohon untuk pemasangan tikung, kesepakatan pembagian wilayah di danau (suak), sanksi perusak pohon, sanksi pencuri sarang lebah madu tikung, upacara sebelum pemanenan, syarat pemanenan lebah madu alam, proses panen lebah madu alam, pengolahan madu alam, proses-proses pengolahan madu alam. Pelestarian pohon pakan lebah madu alam diantaranya; penetapan kawasan Siawan Belida dalam pengelolaan madu tikung, jenis pakan untuk lebah Apis dorsata. Terdapat 9 jenis pohon yang menghasilkan bunga untuk pakan lebah mad alam, dua diantaranya yang paling dominan adalah Putat (Barringtonia actutangula) dan kayu tahun (Garcinia sp)

2. Pemanenan dilakukan sebanyak 2 tahun sekali., diperkirakan jumlahnya 100-150 kg untuk satu periau dalam waktu sekali panen, total yang didapatkan 5-8 ton per tahun. Namun, di awal tahun 2019 hasil madu yang didapat dalam sekali panen sebanyak 5-10 ton 
dikarenakan hasil pakan lebah madu yang melimpah.

\section{SARAN}

Diperlukannya alat untuk mengurangi kadar air pada madu di Desa Nanga Tuan dan diperlukan nya akses komunikasi agar mempermudah dalam pemasaran.

\section{DAFTAR PUSTAKA}

Aprianto A. 2008. Komparasi Kearifan

Tradisional Masyarakat Adat Kasepuhan Cibedug Dengan Aturan Formal Pengelolaan Taman Nasional Gunung Halimun Salak. Bogor : Departemen Konservasi Sumberdaya Hutan dan Ekowisata Institut Pertanian Bogor.

FORCLIME. 2017. Pelatihan Teknik Panen Lestari HHBK Lebah Madu Tikung di Desa Bunut Hulu, Kecamatan Bunut Hilir pada areal DA REDD+ Putaran Kedua DA\#8. Kapuas Hulu : Kabupaten Kapuas Hulu Provinsi Kalimantan Barat. Forclime FC.

Julmansyah. 2010. Madu Hutan Menekan Deforestasi. Jalan Lain Konservasi DAS dan Adaptasi Perubahan Iklim. Jaringan Madu Hutan Sumbawa (JMHS). Pondok Madu Rakyat Desa Batudulang. Kecamatan Batulanteh, NTB. http://labbadas.sumbawakab.do.id /statis-1-profil.html

November 2018)

http://sumbawakab.bps.go.id November 2018)

Kuntadi HS. 2007. Kearifan Tradisional Dalam
"BUDIDAYA" Lebah Hutan (Apis dorsata). Bogor: Departemen Kehutanan, Badan Penelitian dan Pengembangan Kehutanan, Pusat Penelitian dan Pengembangan Hutan dan Kawasan Konservasi Alam.

Santoso, Imam. 2006. Eksistensi kearifan lokal pada petani tepian hutan dalam mememlihara kelestarian ekosistem sumber daya hutan. Jurnal Wawasan.11 (3) : 10-20.

Sartini. 2004. Menggali kearifan lokal. Jurnal Filsafat. 14 (2) : 111-120

Soerjono, Soekanto. 2006. Sosiologi Suatu Pengantar. Jakarta: Raja Grafindo Persada.

Suhartini. 2009. Kajian Kearifan Lokal Masyarakat dalam Pengelolaan Sumber Daya Alam dan Lingkungan. Prosiding Seminar Nasional Penelitian Pendidikan dan Penerapan MIPA, Fakultas MIPA, Universitas Negeri Yogyakarta. B206-B218

Widhiono, M.Z., 1986. Faktor-faktor Lingkungan yang Berpengaruh Terhadap Penambahan Sel dalam Sisiran Lebah Madu. Prosiding Lokakarya Pembudidayaan Lebah Madu untuk Peningkatan Kesejahteraan Masyarakat. Perum Perhutani, Jakarta. Halaman 3941

Yayasan Riak Bumi. 2012. Pakan Lebah Hutan Danau Sentarum. htpp://riakbumi.or.id/index.php/ne ws/64-pakan-lebah-hutan-danausentarum (25 November 2018) 